\title{
Characterization of Tar From Wood Pellet Production
}

\author{
Gurkaran S. Sarohia ${ }^{1}$, Harpuneet S. Ghuman ${ }^{1}$, Adrian K. James ${ }^{1}$, Ronald W. Thring ${ }^{1} \&$ Guy L. Plourde ${ }^{2}$ \\ ${ }^{1}$ Department of Environmental Science and Engineering, University of Northern British Columbia, Prince \\ George, British Columbia, Canada \\ ${ }^{2}$ Department of Chemistry, University of Northern British Columbia, Prince George, British Columbia, Canada \\ Correspondence: Ronald W. Thring, Department of Environmental Science and Engineering, University of \\ Northern British Columbia, Prince George, British Columbia, Canada. Tel: 1-250-960-5804. E-mail: \\ thring@unbc.ca
}

Received: July 10, 2014 Accepted: August 8, 2014 Online Published: August 26, 2014

doi:10.5539/ijc.v6n4p1 URL: http://dx.doi.org/10.5539/ijc.v6n4p1

\begin{abstract}
In recent years, there has been an increased shift towards using renewable biomass as a source of energy generation. Wood pellets are widely used for energy production and are manufactured by densifying wood into pellets for increased energy efficiency. The manufacturing process of these pellets typically generates a tar-like byproduct resulting in increased production costs associated with waste disposal, equipment clean-up and handling operations. The current study focuses on characterization of this wood-based tar, which can create significant technological problems and environmental hazards. The tar was characterized by gas chromatography-mass spectrometry (GC-MS), thermogravimetric analysis (TGA), ${ }^{1} \mathrm{H}$ nuclear magnetic resonance spectroscopy $\left({ }^{1} \mathrm{H}-\mathrm{NMR}\right)$, infrared spectroscopy (IR), solubility and moisture content. A total of 29 compounds were identified.
\end{abstract}

Keywords: wood, pellets, tar, distillation, gas chromatography, mass spectrometry, resin acids

\section{Introduction}

The generation of waste products by agricultural, industrial, commercial and domestic activities, make waste by-products an inevitable part of life. Due to an increase in environmental and sustainability issues, the treatment of such wastes is becoming of increasing importance. Today, recycling of waste by-products is preferred over their disposal due to the issues pertaining to landfills, water management and air quality. A report published by Environment Canada in 1991 stated that 30 million tons of solid waste were produced annually (Crowe \& Ptacek, 2008). This waste has an enormous impact on water systems and therefore disposal has to be carefully monitored (Crowe \& Ptacek, 2008). For these reasons, new methods of recycling and disposal need to be explored.

One such category of waste produced in significant quantity is wood tars. These tars are usually dark, thick flammable liquids that consist of a mixture of hydrocarbons, alcohols and other organic compounds (Milne, Evans, \& Abatzoglou, 1998). Wood tars can cause many industrial problems such as blockages in engines, turbines and pipelines, causing machine failures and damaging engines (Hosoya, Kawamoto, \& Saka, 2008; Devi, Ptasinski, \& Janssen, 2003). Wood tars are produced in a variety of industrial processes and their compositions vary depending on the type of process, temperature of maturation and other factors (Blanco, Wu, Onwudili, \& Williams, 2012).

Pellet production is a process that leads to the formation of wood tars. With the growing need for renewable fuels the demand for wood pellets is rapidly increasing across the world (Envirochem services INC., 2010). Furthermore, this growing demand has led to the construction of wood pellet plants in residue rich countries such as Canada (Scott, 2009). With the large forestry resource available in British Columbia, the province has seen rapid expansion in pellet manufacturing plants (Scott, 2009).

The wood pellets are made of waste material from lumber and sawmills. The production of wood pellets is composed of 5 stages: drying, milling, pressing, cooling and screening (Envirochem services INC., 2010; Scott, 2009). In the initial drying stage the wood chips which are high in moisture content (50-65\%) need to be dried in order to reduce machine wear (Scott, 2009). This is normally done with rotary dryers using either a single-pass or multiple-pass technique (Envirochem services INC., 2010). During the drying stage volatile organic 
compounds as well as condensable particulate matter (CPM) are often produced (Envirochem services INC., 2010). These CPM fractions which include sticky tars can cause machine failures by sticking to filters and blocking machinery (Envirochem Services Inc., 2010). In order to deal with the potential environmental and clean-up problems associated with the tar produced, knowledge of its physical and chemical characteristics is necessary. Furthermore, characterization of the tar might be useful in identifying economically beneficial chemicals such as poly aromatic hydrocarbons (PAH's), resin acids or other oxygenated compounds.

The present article describes the structural and chemical characterization of a by-product tar, produced at a pellet plant located in Northern British Columbia, Canada. Short path vacuum distillation was used to fractionate the tar into various fractions based on boiling points. Analytical techniques such as moisture analysis, gas chromatography-mass spectrometry (GC-MS), thermogravimetric analysis (TGA), infrared spectroscopy (IR) and proton nuclear magnetic resonance $\left({ }^{1} \mathrm{H}-\mathrm{NMR}\right)$ were used in our analysis of the by-product tar.

\section{Methods}

\subsection{Samples}

The AR tar (as received tar) used for this study was obtained from the Pinnacle Pellet plant located near Quesnel, British Columbia, Canada. This plant produces pellets using sawdust obtained from coniferous wood sources. The AR tar was obtained from the condensate produced during the drying stage. The sample was collected in a plastic container which was stored in the dark at room temperature.

\subsubsection{Fractionating Method}

Short path distillation was used to thermally separate the compounds present based on their boiling points and was carried out under vacuum (Hickman, 1944). The low pressure used decreases the atmospheric boiling points of the compounds and forces them to distill at lower temperatures which help in the collection of heat sensitive as well as high boiling compounds.

The AR tar was stirred to ensure homogeneity and a sample $(15.76 \mathrm{~g})$ was distilled under vacuum $\left(10^{-1}\right.$ torr $)$ in a Kugelrohr distillation apparatus purchased from Sigma Aldrich. The fractions were collected at $75{ }^{\circ} \mathrm{C}, 100{ }^{\circ} \mathrm{C}$, $125{ }^{\circ} \mathrm{C}, 150{ }^{\circ} \mathrm{C}, 175{ }^{\circ} \mathrm{C}, 230^{\circ} \mathrm{C},>230{ }^{\circ} \mathrm{C}$ and were labeled A, B, C, D, E, F, G respectively. After the specific temperature was reached, the temperature was held constant for a period of 30 minutes.

\subsection{Analytical Techniques}

The following techniques were used to identify the components from the fractionated tar samples: gas chromatography-mass spectrometry (GC-MS), thermogravimetric analysis (TGA), proton nuclear magnetic resonance spectroscopy ( $\left.{ }^{1} \mathrm{H}-\mathrm{NMR}\right)$, infrared spectroscopy (IR), solubility and moisture content.

\subsubsection{Moisture Content Analysis}

Approximately $1 \mathrm{~g}$ of AR tar was heated at $105{ }^{\circ} \mathrm{C}$ for a period of 72 hours. The moisture content was determined by difference of the initial and final weights. The analysis was repeated three times and the average is reported. This analysis assumes that only water escapes at this temperature and does not correct the data for potential mass changes due to volatile material.

\subsubsection{Solubility}

Approximately $5 \mathrm{~g}$ of the $\mathrm{AR}$ tar and $10 \mathrm{~mL}$ of the solvent being used for the analysis were placed in a pre-weighed $25 \mathrm{~mL}$ vial. The vial was set to shake at $300 \mathrm{rpm}$ at a constant temperature of $25^{\circ} \mathrm{C}$. After 1 hour, the solvent was decanted and filtered through a Whatman 2 filter paper $(55 \mathrm{~mm}$, qualitative). The vial and the filter paper were air dried at room temperature for 72 hours. The solubility was measured by difference of the initial and final tar weights that was left on the filter paper and vial.

\subsubsection{Thermogravimetric Analysis (TGA)}

The thermal characteristics were determined using a TGA-50/50H Shimadzu thermogravimetric analyzer. The analyses were conducted using air at a flow rate of $50 \mathrm{~mL} / \mathrm{min}$, under atmospheric conditions. For each test, approximately $10 \mathrm{mg}$ of the sample was heated from room temperature to $800{ }^{\circ} \mathrm{C}$ with a heating rate of 10 ${ }^{\circ} \mathrm{C} / \mathrm{min}$. The thermogravimetric (TGA) plot describes the weight loss of the sample with increasing temperature while the differential thermogravimetric (DTG) plot illustrates the derivative of the sample mass with time at a specific temperature.

\subsubsection{Gas Chromatography-Mass Spectrometry (GC-MS)}

The GC-MS instrumentation consisted of a Varian gas chromatograph equipped with a Saturn 2200 mass spectrometer. The separations were performed on a capillary column $(30 \mathrm{~m} \times 0.25 \mathrm{~mm}$ i.d., 0.25 micrometer; 
Varian). The oven temperature was programmed from 50 to $100{ }^{\circ} \mathrm{C}$ at $15{ }^{\circ} \mathrm{C} / \mathrm{min}$ and from 100 to $300{ }^{\circ} \mathrm{C}$ at $10{ }^{\circ} \mathrm{C} / \mathrm{min}$ and finally held at $300{ }^{\circ} \mathrm{C}$ for 17 minutes. Splitless injections of $1 \mu \mathrm{L}$ were performed at $300{ }^{\circ} \mathrm{C}$ with an autosampler (Varian). The mass spectrometer was operated in electron impact (EI) mode with a $40-650 \mathrm{~m} / \mathrm{z}$ range.

\subsubsection{Nuclear Magnetic Resonance Spectroscopy ( ${ }^{1}$ H-NMR)}

The tar samples were also analyzed by proton nuclear magnetic resonance spectroscopy to determine the presence of potential functional groups. The ${ }^{1} \mathrm{H}-\mathrm{NMR}$ analysis was performed using a Bruker 300 Fourier NMR spectrometer $(300 \mathrm{MHz})$. The samples were dissolved in deuterated chloroform $\left(\mathrm{CDCl}_{3}\right)$.

\subsubsection{Fourier Transform Infrared Spectroscopy (FTIR)}

The FTIR analysis was performed using a Perkin Elmer 2000 system to confirm the potential functional groups. The FTIR spectra were recorded within the region 4000 to $650 \mathrm{~cm}^{-1}$. Spectra were recorded neat by placing each sample between 2 sodium chloride $(\mathrm{NaCl})$ discs.

\section{Results and Discussion}

Identification of the compounds present in tars is usually achieved by GC-MS (Blanco et al., 2012; Jiang, Q. Wang, Y. Wang, Tong, \& Xiao, 2007). Apart from GC-MS other techniques such as TGA and ${ }^{1} \mathrm{H}-\mathrm{NMR}$ can also be used to complement GC-MS data. However, since these analytical techniques require that the samples be dissolved in a solvent, a solubility test using the following common solvents (pentane, toluene, methanol, ethanol, acetone, water) was performed. This solubility test demonstrated that the AR tar sample was not fully soluble in any of the solvents tested (see Table 1). Therefore, it was deemed necessary to carry out a fractionation of the AR tar in order to obtain material which would dissolve in common solvents.

\subsection{Solubility}

Table 1 shows the solubility of AR tar in each solvent. The solvents are listed in increasing order of polarity (Murov, 2014). Tar was found to be most soluble in acetone $(0.412 \mathrm{~g} / \mathrm{mL})$ and least soluble in water $(0.007$ $\mathrm{g} / \mathrm{mL})$. The solubility of tar was comparable in toluene $(0.296 \mathrm{~g} / \mathrm{mL})$ and ethanol $(0.293 \mathrm{~g} / \mathrm{mL})$ whereas, tar was slightly less soluble in pentane $(0.211 \mathrm{~g} / \mathrm{mL})$ and methanol $(0.193 \mathrm{~g} / \mathrm{mL})$. With the buildup of tar in pellet producing machinery, the cleanup and removal of such waste is imperative. Based on the relatively low cost (Table 1) and low toxicity, ethanol may be a suitable solvent for cleanup at the pellet plant (NAFAA, 2001).

Table 1 . The solubility analysis of AR tar in various solvents

\begin{tabular}{cccc}
\hline Solvent & Solubility $(\mathrm{g} / \mathrm{mL})$ & Boiling Point $\left({ }^{\circ} \mathrm{C}\right)$ & $\begin{array}{c}\text { Bulk cost of solvent }(\$ / \mathrm{L}) \\
(\text { ICIS 2013) }\end{array}$ \\
\hline Pentane & 0.211 & 36.1 & - \\
Toluene & 0.296 & 110.6 & $0.74-1.05$ \\
Methanol & 0.193 & 64.7 & $0.25-0.67$ \\
Ethanol & 0.293 & 78.4 & $0.56-1.03$ \\
Acetone & 0.412 & 56.0 & $1.03-1.81$ \\
Water & 0.00721 & 100.0 & - \\
\hline
\end{tabular}

\subsection{Moisture Analysis and Distillation}

Short path distillation was used to fractionate the AR tar. Short path distillation thermally separates the compounds present based on their boiling points at low pressure (Hickman, 1994). Table 2 shows the wt \% of the tar fractions obtained from distillation. The first four fractions (A-D) with boiling point up to $150{ }^{\circ} \mathrm{C}$ were considered to contain the volatile material. As seen in Table 2, the first fraction collected at $75{ }^{\circ} \mathrm{C}$ (fraction A) only represented $<1 \%$ by weight of the AR tar, while fractions $\mathrm{B}\left(100{ }^{\circ} \mathrm{C}\right)$ and $\mathrm{C}\left(125^{\circ} \mathrm{C}\right)$ consisted of $\sim 6 \%$ and $\sim 12 \%$, respectively. The highest amounts of volatiles were obtained in Fraction $\mathrm{D}\left(150{ }^{\circ} \mathrm{C}\right)$ accounting for $\sim$ $17 \%$ of the sample weight. The higher boiling fractions $\mathrm{E}$ and $\mathrm{F}$ were darker in color and appeared to be more viscous. The last fraction collected at $230{ }^{\circ} \mathrm{C}$ accounted for $\sim 10 \%$ of the sample weight, leaving a char-like black solid behind. This solid contributed $\sim 30 \%$ to the overall weight of the sample. The unrecovered sample mass contributed $\sim 19 \%$ of the sample weight and could have been due to the presence of water and very 
volatile compounds that did not condense in the distillation process.

Table 2. Recovered mass of various distillate fractions of wood $\operatorname{tar}^{1}$

\begin{tabular}{cccc}
\hline Fraction $^{2}$ & Mass (g) & Yield (wt \% of AR tar) & Physical observation \\
\hline A & 0.100 & 0.64 & Yellow Liquid \\
B & 0.871 & 5.56 & Viscous yellow liquid \\
C & 1.823 & 11.63 & Yellow semi solid \\
D & 2.643 & 16.86 & Brown semi solid \\
E & 0.900 & 5.74 & Brown semi solid \\
F & 1.570 & 10.02 & Brown semi solid \\
G & 4.708 & 30.03 & Black char-like solid \\
\hline
\end{tabular}

${ }^{1} 15.76 \mathrm{~g}$ of AR tar was used; ${ }^{2}$ temperature range per fraction: A: up to $75^{\circ} \mathrm{C}, \mathrm{B}: 76-100{ }^{\circ} \mathrm{C}, \mathrm{C}: 101-125^{\circ} \mathrm{C}, \mathrm{D}$ :

126- $150{ }^{\circ} \mathrm{C}, \mathrm{E}: 151-175^{\circ} \mathrm{C}, \mathrm{F}: 176-230^{\circ} \mathrm{C}, \mathrm{G}:>230^{\circ} \mathrm{C}$.

\subsection{Gas Chromatography-Mass Spectrometry (GC-MS)}

Figure 1 shows gas chromatographs of the various fractions obtained after short path distillation of AR tar. As can be seen in Figure 1, many peaks overlap across the various fractions indicating that the short path distillation was unable to completely isolate the compounds into specific fractions. Tar, being a wood residue, potentially contains a large variety of compounds making it difficult to completely separate them into fractions based on boiling point alone. Therefore, simple distillation techniques do not appear to be able to completely fractionate compounds without overlaps. However, Figure 1 suggests that the fractionating technique used was able to provide for a small segregation between volatile and semi-volatile material since most compounds present in the low boiling fractions (A-D) are not found in the higher boiling fractions (E and F).

Table 3 shows the possible components present in each fraction of the tar. By correlating the GC-MS data to the NIST database (National Institute of Standards and Technology) a total of 29 compounds were identified. Low boiling point fractions A and B contained 15 out of the total 29 compounds identified. The compounds of these two fractions were mostly aldehydes, ketones, alkenes and aromatic in nature. Similar compounds were also identified to populate fraction C. Furthermore, fraction $\mathrm{C}\left(125^{\circ} \mathrm{C}\right)$ appears to be the threshold point in the distillation process. Most compounds in the higher boiling fractions (D-F) are not found in the lower boiling fractions (A-B). The higher boiling fractions (D, E, and F) were composed mainly of carboxylic acids and were especially concentrated in resin acids such as abietic acid, palusteric acid, and pimaric acid. These resin acids are a complex mixture that mainly contains monocarboxylic acids of alkylated hydrophenanthrene structures (Hudy, 1959). Further isolation of the specific acids such as Abietic acid has been discussed in previous studies (Harris \& Sanderson, 1948) since such resin acids could cause a problem in disposal of tar due to their toxicity to fish and microorganisms (Wang, Chen, Gao, Breuil, \& Hiratsuka, 1995; Peng \& Roberts, 2000; Villeneuve, Yagminas, Marino, \& Becking, 1977). 


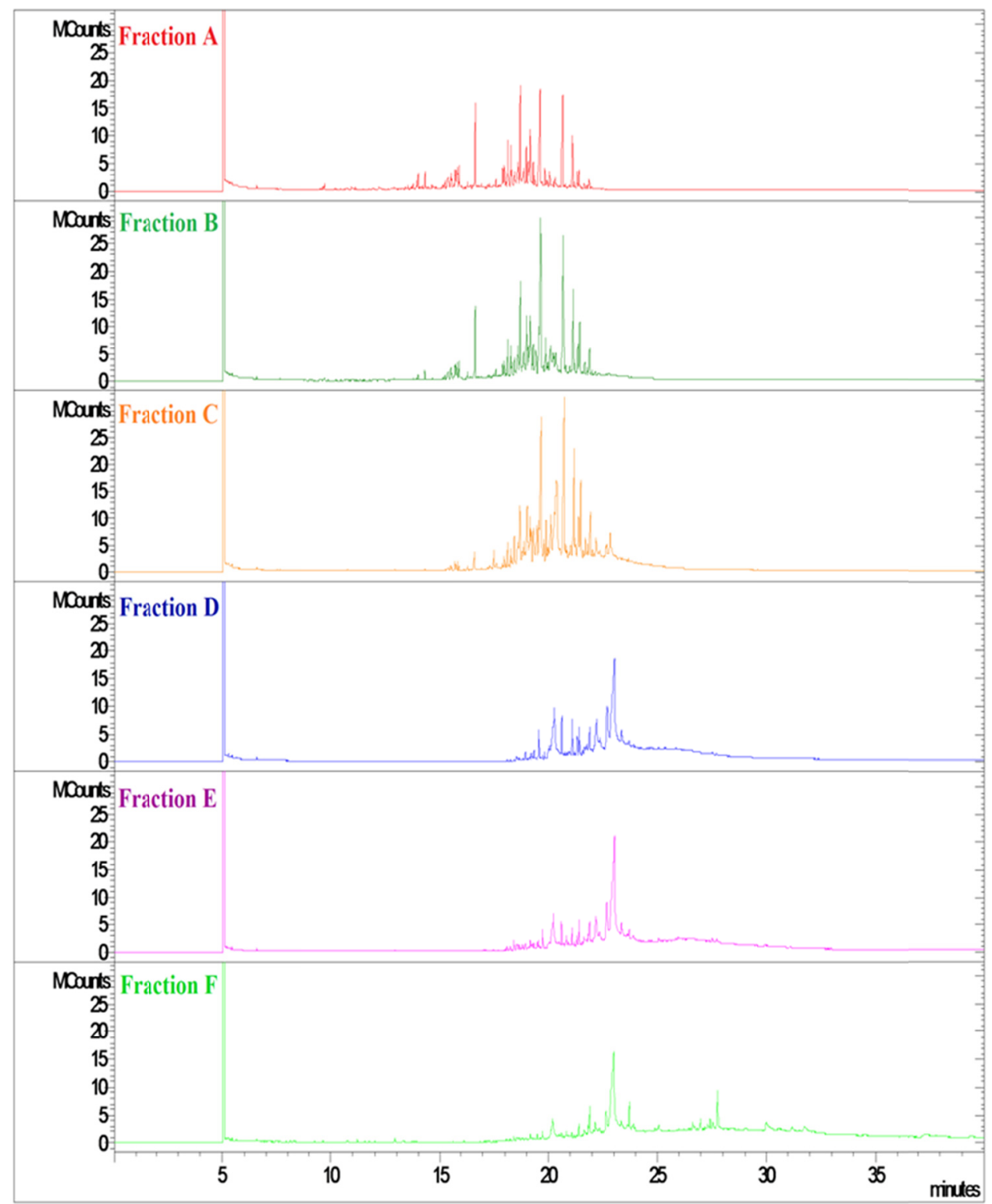

Figure 1. Gas chromatographs of various distillate fractions of wood tar

Table 3. Major components of various wood tar fractions identified using the NIST GC-MS library

\begin{tabular}{|c|c|c|c|c|c|c|c|c|}
\hline $\begin{array}{l}\text { Peak } \\
\text { no. }\end{array}$ & $\begin{array}{l}\text { Retention } \\
\text { Time (min) }\end{array}$ & $\begin{array}{l}\text { MW } \\
(\mathrm{g} / \mathrm{mol})\end{array}$ & Possible component & A & B & $\mathrm{C}$ & $\mathrm{D}$ & $\mathrm{E}$ \\
\hline 1 & 15.86 & 494 & $\begin{array}{c}\text { 4-Norcaren-2-one,1,3,5-tri-tert-butyl-3- } \\
\text { (3,5-di-tert-butyl-4-h }\end{array}$ & $*$ & & & & \\
\hline 2 & 15.944 & 234 & 1-Tetralone, 8-trimethylsilyloxy- & $*$ & & & & \\
\hline 3 & 16.665 & 219 & 2-Phenyl-6-vinylindolizine & $*$ & $*$ & & & \\
\hline 4 & 16.665 & 219 & Androst-2,16-diene & $*$ & $*$ & & & \\
\hline 5 & 18.733 & 272 & $\begin{array}{l}\text { Naphthalene,decahydro-1,1,4a-trimethyl-6- } \\
\text { methylene-5-(3-methyl }\end{array}$ & $*$ & $*$ & $*$ & & \\
\hline 6 & 18.878 & 410 & $\begin{array}{c}\text { 6-Methyl-11,12-dioxatricyclo[7.2.1.0(1,6)]dodecan-5-ol-8 } \\
\text {-carbox }\end{array}$ & & * & & & \\
\hline
\end{tabular}




\begin{tabular}{|c|c|c|c|c|c|c|c|c|c|}
\hline 7 & 18.99 & 266 & $\begin{array}{l}\text { 1-Cyclohexene-1-carboxylic acid, } \\
\text { 4-(1,5-dimethyl-3-oxohexyl)-, }\end{array}$ & * & $*$ & $*$ & & & \\
\hline 8 & 19.02 & 207 & 4-(Diethylaminomethyl)-2,5-dimethylphenol & & $*$ & & & & \\
\hline 9 & 19.045 & 293 & Benzothiazole, 2-(2,6-dimethyl-1-morpholyl)-6-nitro- & & & * & & & \\
\hline 10 & 19.077 & 290 & $\begin{array}{l}\text { 1H-Naphtho[2,1-b]pyran, } \\
\text { 3-ethenyldodecahydro-3,4a,7,7,10a-penta }\end{array}$ & * & $*$ & & & & \\
\hline 11 & 19.152 & 272 & $\begin{array}{c}\text { Phenanthrene, } \\
\text { 7-ethenyl-1,2,3,4,4a,4b,5,6,7,9,10,10a-dodecahydro }\end{array}$ & * & $*$ & $*$ & & & \\
\hline 12 & 19.209 & 506 & $\begin{array}{l}\text { Olean-12-ene-3,16,21,22,23,28-hexol, } \\
\text { (3.beta.,4.beta.,16.alpha) }\end{array}$ & & & $*$ & & & \\
\hline 13 & 19.306 & 290 & $\begin{array}{l}\text { 1H-Naphtho[2,1-b]pyran, } \\
\text { 3-ethenyldodecahydro-3,4a,7,7,10a-penta }\end{array}$ & * & $*$ & $*$ & & & \\
\hline 14 & 19.62 & 290 & $\begin{array}{l}\text { 1-Naphthalenepropanol, .alpha.-ethenyldecahydro- } \\
\text {.alpha.,5,5,8a- }\end{array}$ & * & $*$ & * & $*$ & & \\
\hline 15 & 19.466 & 282 & $\begin{array}{l}\text { 1,2,3-Benzenetricarboxylic acid, 4-hydroxy-5-methyl-, } \\
\text { trimethyl }\end{array}$ & & & * & & & \\
\hline 16 & 19.79 & 299 & $\begin{array}{l}\text { 10-Formamido-10,11-dihydro-2,3-dimethoxydibenz } \\
\text { (b,f)oxepin }\end{array}$ & & & $*$ & & & \\
\hline 17 & 19.87 & 292 & 5.alpha.-Androstane, 1,3-dihydroxy-, (1.alpha.,3.alpha.)- & & $*$ & $*$ & & & \\
\hline 18 & 20.095 & 398 & 28-Nor-17.alpha.(H)-hopane & & & $*$ & & & \\
\hline 19 & 20.284 & 562 & Oleic acid, eicosyl ester & & & $*$ & $*$ & $*$ & $*$ \\
\hline 20 & 20.656 & 286 & $\begin{array}{l}\text { 1-Phenanthrenecarboxaldehyde, } \\
\text { 7-ethenyl-1,2,3,4,4a,4b,5,6,7,9,10 }\end{array}$ & $*$ & $*$ & $*$ & $*$ & & \\
\hline 21 & 21.032 & 288 & Podocarp-7-en-3.beta.-ol, 13.beta.-methyl-13-vinyl- & & & $*$ & & & \\
\hline 22 & 21.166 & 286 & Retinol & & & $*$ & & & \\
\hline 23 & 21.471 & 288 & $\begin{array}{l}\text { 19-Hydroxy-3alpha,5-cyclo-5alpha-androstan- } \\
\text { 17-one }\end{array}$ & & & $*$ & & & \\
\hline 24 & 22.186 & 302 & Pimaric acid & & & $*$ & $*$ & $*$ & \\
\hline 25 & 22.696 & 302 & Paulstric acid & & & & $*$ & $*$ & * \\
\hline 26 & 22.873 & 300 & $\begin{array}{l}\text { 1-Phenanthrenecarboxylic acid, } \\
1,2,3,4,4 \mathrm{a}, 9,10,10 \text { a-octahydro-1 }\end{array}$ & & & $*$ & & $*$ & * \\
\hline 27 & 23.374 & 302 & Abietic acid & & & & $*$ & $*$ & \\
\hline 28 & 23.726 & 328 & 7-Oxodehydroabietic acid, methyl ester & & & & & & * \\
\hline 29 & 27.755 & 456 & beta.-Sitosterol acetate & & & & & & * \\
\hline
\end{tabular}

\subsection{Thermogravimetric Analysis (TGA)}

Figure 2 and Table 4 show the thermal degradation of the tar in air at a constant heating rate. The derivative thermogravimetric analysis (drTGA) curve (Figure 2) shows three major mass losses that occur within the ranges 200-300 ${ }^{\circ} \mathrm{C}, 300-420{ }^{\circ} \mathrm{C}$ and $420-500{ }^{\circ} \mathrm{C}$. The first volatile release occurs at $200-300{ }^{\circ} \mathrm{C}$ and the second volatile release occurs between $300-420{ }^{\circ} \mathrm{C}$. The weight loss at temperature $200-300{ }^{\circ} \mathrm{C}$ was $\sim 28 \%$ while $\sim 31 \%$ weight loss was observed at temperature $300-420{ }^{\circ} \mathrm{C}$. The final weight loss is observed at temperature of $420{ }^{\circ} \mathrm{C}$ and above contributing to $\sim 35 \%$. The weight losses for temperatures over $380{ }^{\circ} \mathrm{C}$ contributed to $\sim 47 \%$ of the total weight. This weight loss can be attributed to some resin acids and char. This conclusion is based on the fact that the AR tar main wood source was coniferous in nature and other studies have reported the presence of resin acids in coniferous plants (Funk \& Croteau, 1994). Furthermore, the boiling point of the resin acids is usually greater than $400{ }^{\circ} \mathrm{C}$ at atmospheric pressure and as such major mass loss after $400{ }^{\circ} \mathrm{C}$ can be attributed to the resin acids (CRC Handbook of Chemistry and Physics 2012-2013). As seen from Table 3 the GC-MS data also verifies the 
presence of resin acids in the higher boiling tar fractions. These compounds are of wood origin, and have a high probability of being present in the tar, which is a by-product of a wood pellet manufacturing operation. Furthrmore, previous studies indicate that the char oxidation occurs at $\sim 400{ }^{\circ} \mathrm{C}$ in lignocellulosic samples (Elder, Kush, \& Hermann, 2011; Blasi, 2009). This indicates that char might be present in the sample. The residual black mass observed during distillation might be attributed to char.

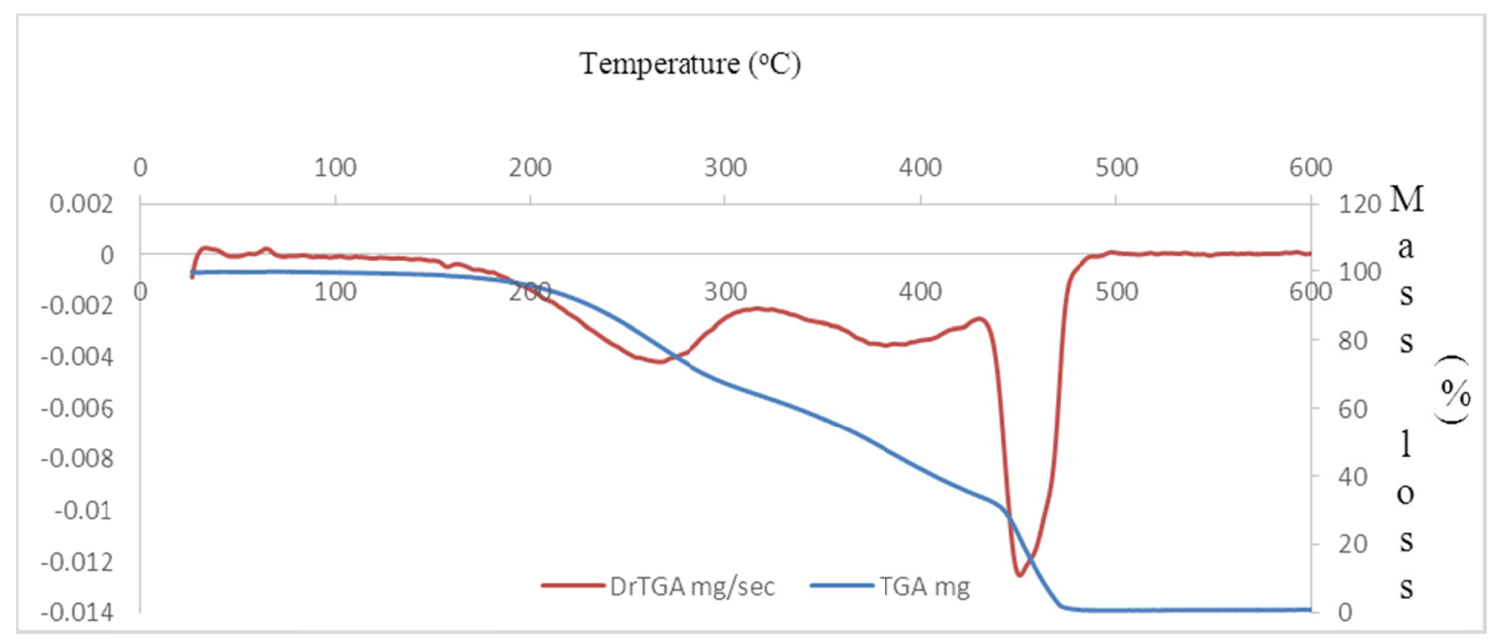

Figure 2. Thermogravimetric analysis curve with the derivative TGA of the wood tar

Table 4. Weight losses of the AR tar analyzed through thermogravimetric analysis.

\begin{tabular}{cc}
\hline Temperature $\left({ }^{\circ} \mathrm{C}\right)$ & $\mathrm{Wt}$ loss $(\%)$ \\
\hline$<200$ & 4.22 \\
$200-250$ & 11.79 \\
$250-300$ & 16.61 \\
$300-350$ & 10.50 \\
$350-400$ & 14.79 \\
$400-450$ & 19.62 \\
$450-500$ & 21.74 \\
\hline
\end{tabular}

\subsection{Nuclear Magnetic Resonance Spectroscopy ( ${ }^{\mathrm{H}} \mathrm{H}-\mathrm{NMR}$ )}

The solution state ${ }^{1} \mathrm{H}-\mathrm{NMR}$ spectrum of each distillate fraction (A-F) was obtained in $1 \mathrm{~mL}$ deuterated chloroform. The overlaid ${ }^{1} \mathrm{H}-\mathrm{NMR}$ spectra of each distillate fraction are presented in Figure 3. The NMR spectra can be divided into 6 parts to identify the potential functional groups: aldehyde functional groups (10-9 ppm), aromatics (9-6.5 ppm), phenolics (6.5-5.5 ppm), olefinic (5.5-4.5 ppm), benzylic (4.5-3.3 ppm) and aliphatic (3.3-0.0 ppm). The listed NMR spectra were obtained from 0-10 ppm. As can been seen from Figure 3, the aldehyde proton (10-9 ppm) disappeared in the higher boiling fractions $\mathrm{D}, \mathrm{E}$ and $\mathrm{F}$, indicating that there were very few compounds containing the aldehyde functional group present in the higher boiling fractions. GC-MS and TGA showed that the higher boiling fractions were mostly composed of resin acids. Resin acids do not have any aldehyde functional groups present in their structures and only contain carboxylic acid protons (Fieser \& Campbell, 1938; Morales, Birkholz, \& Hrudy, 1992). Therefore, the NMR spectra agree with the data obtained from GC-MS and TGA. The NMR analysis also suggests the presence of more benzylic protons (4.5-3.3 ppm) in the lower boiling fractions (A-C) than in the high boiling ones (D-F). Once again this is also in agreement with the GC-MS data previously discussed (Table 3). Furthermore, all fractions contain aromatic protons (7.0-7.5 ppm) while the low boiling fractions A-D appears to contain more olefinic protons (4.5-6.0 ppm), also confirming our results from the GC-MS analysis. 


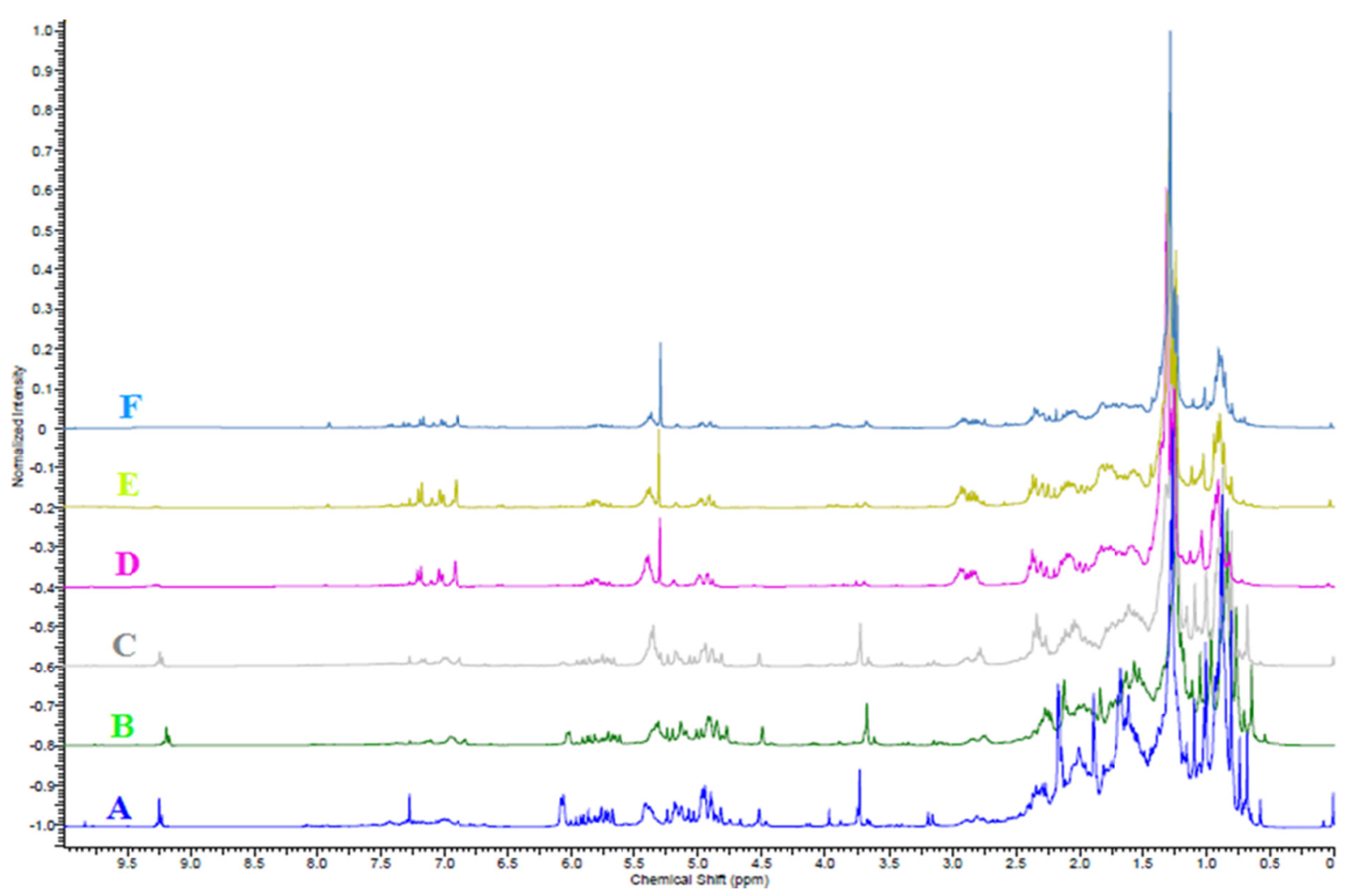

Figure 3. ${ }^{1} \mathrm{H}-\mathrm{NMR}$ spectra of various distillate fractions of wood tar

\subsection{Fourier Transform Infrared Spectroscopy (FTIR)}

FTIR analysis was also carried out in order to confirm the potential chemical functional groups analyzed through ${ }^{1} \mathrm{H}-\mathrm{NMR}$ spectroscopy and GC-MS. The FTIR spectra of distillate fractions $100{ }^{\circ} \mathrm{C}$ and $230{ }^{\circ} \mathrm{C}$ are shown in Figures 4 and 5 as representative examples of the data obtained from FTIR. The spectra of lower boiling fractions A and B (Figure 4) showed bands confirming the presence of aliphatic protons (2949-2848 $\mathrm{cm}^{-1}$ ) and aromatic protons $\left(3076 \mathrm{~cm}^{-1}\right)$. The hydroxyl functional group $\left(3437 \mathrm{~cm}^{-1}\right)$ of alcohols is also observed in the low boiling fractions. The spectra of all fractions show the presence of carbonyl groups $\left(1800-1650 \mathrm{~cm}^{-1}\right)$. However, in the case of the lower boiling fractions (Figure 4), the band at $1715 \mathrm{~cm}^{-1}$ indicates the presence of the carbonyl functional group in compounds such as ketones, aldehydes, conjugated esters and/or carboxylic acids. For the higher boiling fractions (Figure 5), similar absorptions can be observed for aliphatic protons (2953-2852 $\left.\mathrm{cm}^{-1}\right)$, aromatic protons $\left(3076 \mathrm{~cm}^{-1}\right)$ and carbonyls $\left(1723\right.$ and $\left.1697 \mathrm{~cm}^{-1}\right)$. However, the hydroxyl absorption in Figure 5 (portion in the blue box) is much broader than the one found in Figure 4 (see blue box in Figure 4 for comparison). This combination of a broad hydroxyl absorption $\left(3200-2500 \mathrm{~cm}^{-1}\right)$ and a strong carbonyl band at $1698 \mathrm{~cm}^{-1}$ is normally attributed to the carboxylic acid functional group. This broadness of the hydroxyl absorption is due to the strong hydrogen bonding that exists between the molecules of carboxylic acids (Pavia, Lampman, Kriz, \& Vyvyan, 2009). The IR data also confirm our GC-MS results. 


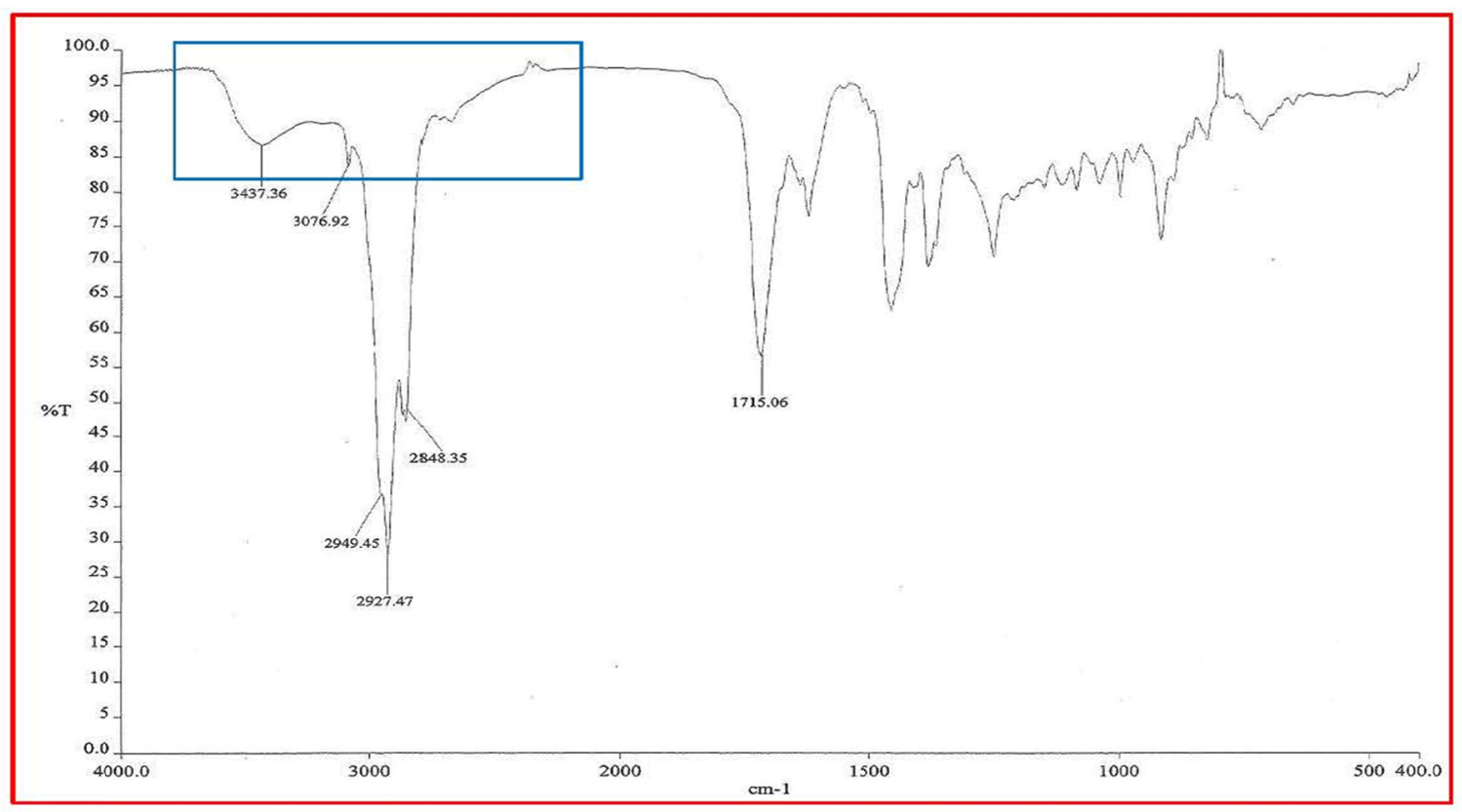

Figure 4. FTIR spectrum of distillate fraction $100{ }^{\circ} \mathrm{C}$

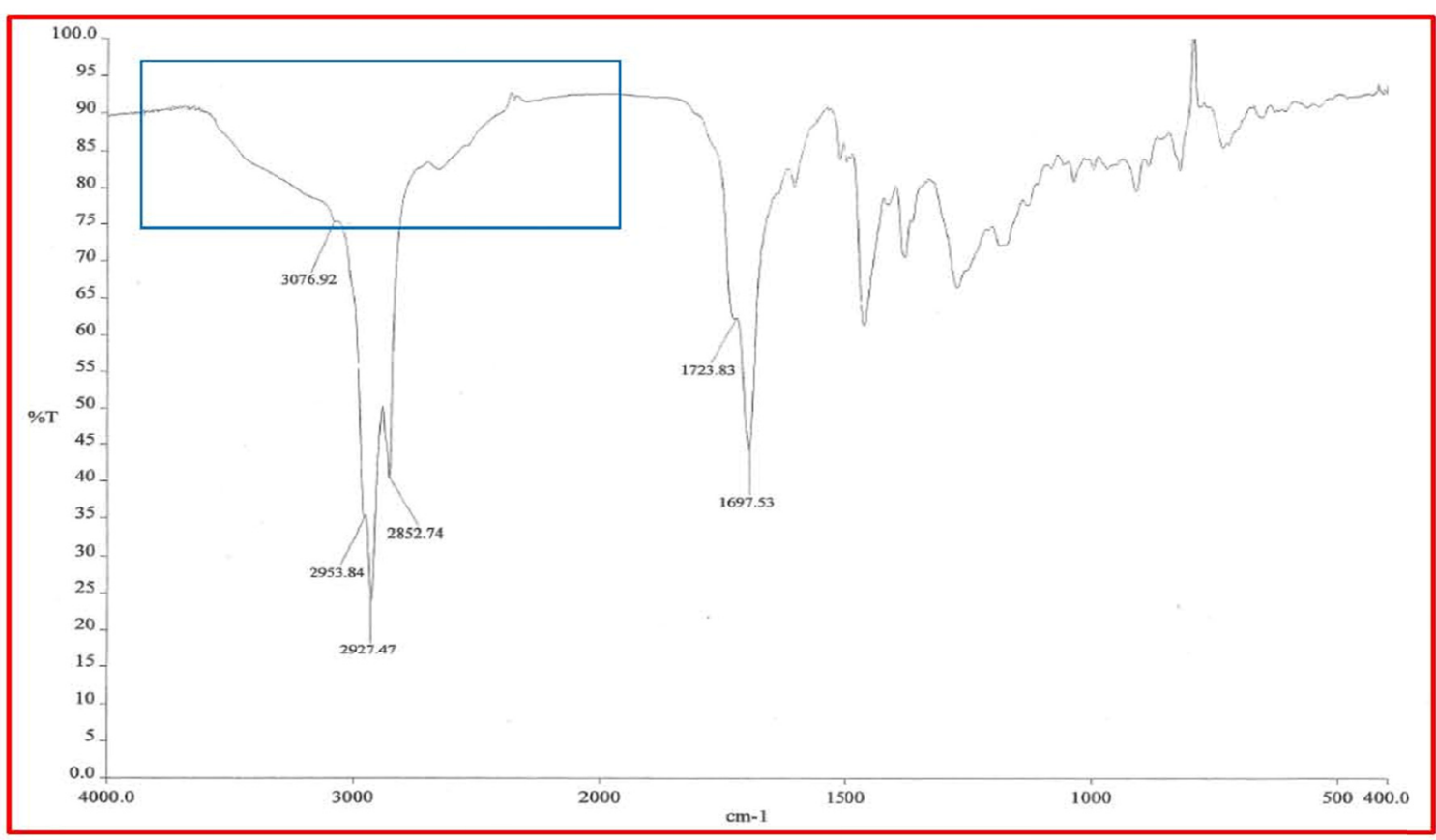

Figure 5. FTIR spectrum of distillate fraction $230{ }^{\circ} \mathrm{C}$

\section{Conclusions}

The proper identification and characterization of environmentally hazardous waste is vital to waste management practices. In this investigation we were able to determine the make-up of the tar produced at a wood pellet manufacturing facilities in British Columbia, Canada. A total of 29 compounds were identified by various analytical techniques (GC-MS, TGA, ${ }^{1} \mathrm{H}-\mathrm{NMR}, \mathrm{FTIR}$ ). Ethanol was also identified as a potential solvent to use in the clean up of machinery due to its low cost as well as low toxicity. To our knowledge, this is the first study of this type dealing with tar produced a pellet plants. 


\section{Acknowledgements}

The authors would like to thank the Natural Sciences and Engineering Research Council of Canada (NSERC) for the financial support. The authors also acknowledge Dr. Quanji Wu and Mr. Charles Bradshaw for helping with various analytical procedures.

\section{References}

Blanco, P. H., Wu, C., Onwudili, J. A., \& Williams, P. T. (2012). Characterization of tar from the Pyrolysis/ Gasification of Refuse Derived Fuel: Influence of Process Parameters and Catalysis. Energy \& Fuels, 26, 2107-2115. http://dx.doi.org/10.1021/ef300031j

Blasi, C. D. (2009). Combustion and gasification rates of lignocellulosic chars. Progess in Energy and Combustion Science, 35, 121-140. http://dx.doi.org/10.1016/j.pecs.2008.08.001

Chips by Wood-inhabiting Fungi. Applied and Environmental Microbiology, 61, 222-225.

Crowe, A. S., \& Ptacek, C. J. (2008). Threats to Sources of Drinking Water and Aquatic Ecosystem Health in Canada. Retrieved December 30, 2012 from (Environment Canada) http://www.ec.gc.ca/inre-nwri/default.asp?lang=En\&n=235D11EB-1\&offset=13\&toc=sh\#cur

Devi, L., Ptasinski, K. J., \& Janssen, F. J. J. G. (2003). A review of the primary measures for tar elimination in biomass gasification processes. Biomass \& Bioenergy, $24, \quad 125-140$. http://dx.doi.org/10.1016/S0961-9534(02)00102-2

Elder, T., Kush, J. S., \& Hermann, S. M. (2011). Thermogravimetric analysis of forest understory grasses. Thermochimica Acta, 512, 170-177. http://dx.doi.org/10.1016/j.tca.2010.10.001

Envirochem Services Inc. (2010). Emissions and Air Pollution Controls for the Biomass Pellet Manufacturing Industry. Retrieved December 30, 2012 from (Vancouver, Canada) http://www.env.gov.bc.ca/epd/industrial/pulp_paper_lumber/pdf/moe-pellet-industry-051410.pdf

Fieser, L. F., \& Campbell, W. P. (1938). Concerning Dehydroabietic Acid and the Structure of Pine Resin Acids. Journal of the American Chemical Society, 60, 159-170. http://dx.doi.org/10.1021/ja01268a050

Funk, C., \& Croteau, R. (1994). Diterpenoid resin acid biosynthesis in conifers: Characterization of two cytochrome P450-dependent monooxygenases and an aldehyde dehydrogenase involved in abietic acid biosynthesis. Archives of Biochemistry and Biophysics, 308, 258-266. http://dx.doi.org/ 10.1006/abbi.1994.1036

Harris, G. C., \& Sanderson, T. F. (1948). Resin Acids. I. An Improved Method of Isolation of Resin Acids; The Isolation of a New Abietic-Type Acid, Neoabietic Acid. Journal of the American Chemical Society, 70, 334-339. http://dx.doi.org/10.1021/ja01181a104

Haynes, W. M. (Ed.) (2012). CRC Handbook of Chemistry and Physics (Vol. 93). Florida: CRC Press: Boca Raton.

Hickman, K. C. D. (1944). High-vacuum Short-path Distillation-A Review. Chemical Reviews, 34, 51-106. http://dx.doi.org/10.1021/cr60107a002

Hosoya, T., Kawamoto, H., \& Saka, S. (2008). Pyrolysis gasification reactivities of primary tar and char fractions from cellulose and lignin as studied with a closed ampoule reactor. Journal of Analytical and Applied Pyrolysis, 83, 71-77. http://dx.doi.org/10.1016/j.jaap.2008.06.002

Hudy, J. A. (1959). Resin Acids. Gas Chromatography of Their Methyl Esters. Analytical Chemistry, 31, 1754-1756. http://dx.doi.org/10.1021/ac60155a017

ICIS. (2013). Indicative chemical prices A-Z. Retrieved April 15, 2013 from http://www.icis.com/chemicals/channel-info-chemicals-a-z/

Jiang, J., Wang, Q., Wang, Y., Tong, W., \& Xiao, B. (2007). GC/MS Analysis of Coal Tar Composition Produced from Coal Pyrolysis. Bulletin of the Chemical Society of Ethiopia, 21, 229-240. http://dx.doi.org/10.4314/bcse.v21i2.21202

Milne, T. A., Evans, R. J., \& Abatzoglou, N. (1998). Biomass Gasifier "Tars": Their Nature, Formation and Conversion. Vol. 570. National Renewable Energy Laboratory, Colorado, USA.

Morales, A., Birkholz, D. A., \& Hrudey, S. E. (1992). Analysis of Pulp Mill Effluent Contaminants in Water, Sediment, and Fish Bile: Fatty and Resin Acids. Water Environment Research, 64, 660-668. http://dx.doi.org/10.2175/WER.64.5.2 
Murov, S. (2014). Properties of Organic Solvents. Retrieved on August 4, 2014 from http://murov.info/orgsolvents.htm

NAFAA-North American Fire Arts Association. (2001). Material Safety Data Sheet. Retrieved on April 17, 2013 from http://www.nafaa.org/ethanol.pdf

Pavia, D. L., Lampman, G. M., Kriz, G. S., \& Vyvyan, J. R. (2009). Introduction to Spectroscopy (4th ed.). Belmont, CA: Brooks-Cole.

Peng, G., \& Roberts, J. C. (2000). Solubility and toxicity of resin acids. Water Research, 34, 2779-2785. http://dx.doi.org/ 10.1016/S0043-1354(99)00406-6

Reed, T. B., \& Gaur, S. (1998). Survery of Biomass Gasification-1998. The National Renewable Energy Laboratory and the Biomass Energy Foundation Inc., Golden, CO, USA.

Scott, W. (2009). An Overview of the Wood Pellet Industry: A British Columbia Perspective. Retrieved December 31, 2013 from https://circle.ubc.ca/bitstream/handle/2429/16863/ScottWill WOOD_493_Graduating_Essay_2008.pdf? sequence=1

Villeneuve, D. C., Yagminas, A. P., Marino, G. C., \& Becking, G. C. (1977). Toxicity studies on dehydroabietic acid. Bulletin of Environmental Contamination and Toxicology, 18, 42-47.

Wang, Z., Chen, T., Gao, Y., Breuil, C., \& Hiratsuka, Y. (1995). Biological Degradation of Resin Acids in Wood Chips by Wood-inhabiting Fungi. Applied and Environmental Microbiology, 61, 222-225.

\section{Copyrights}

Copyright for this article is retained by the author(s), with first publication rights granted to the journal.

This is an open-access article distributed under the terms and conditions of the Creative Commons Attribution license (http://creativecommons.org/licenses/by/3.0/). 